\title{
O SENTIDO DAS RELAÇÕES AMOROSAS NA CONTEMPORANEIDADE
}

\author{
Adriana Martins Rabelo ${ }^{1}$; Ana Lúcia Francisco ${ }^{2}$
}

\section{THE MEANING OF LOVING RELATIONS IN CONTEMPORANEITY}

Resumo: Este artigo tem como objetivo compreender o sentido das relações amorosas na contemporaneidade. Para tanto faremos uma reflexão sobre o que significa amar na atualidade, enfocando algumas transformaçōes ocorridas nas relações amorosas, enfatizando que a forma como estas relações se configuram está intimamente vinculada à paisagem social, cultural e subjetiva da qual fazem parte. Mostraremos que a contemporaneidade é caracterizada por uma cultura que privilegia a maximização do prazer, as relações descartáveis, a luta contra o tempo, a alta competitividade e o consumismo. Salientaremos que a contemporaneidade tem produzido uma subjetividade construída com base na falta de referências. Evidenciaremos que as relaçóes humanas estão cada vez mais frágeis, esperando que o aprofundamento desta temática possa contribuir para situar o papel do psicólogo clínico neste contexto.

Palavras-chave: Relações amorosas;. contemporaneidade; cultura; subjetividade; psicologia clínica.

Abstract: This article's objective is to understand the meaning of contemporaneity's loving relations. For that we will make a reflection on what it means to love in the present time, focusing on some transformations that have occurred in loving relations, emphasizing that the way these relations configure are closely tied with the social, cultural and subjective landscape of which they

\footnotetext{
Psicóloga clínica e psicoterapeuta, Especialista em Psicologia da Família e em Intervenções Clínicas em Psicologia. e-mail:wmrabelo@terra.com.br

2 Profa. Dra. Docente da graduação e pós-graduação do departamento de psicologia da Universidade Católica de Pernambuco - UNICAP. Coordenadora da linha de pesquisa "Práticas Psicológicas em Instituições" e Líder do grupo de pesquisa em Psicologia clínica. e-mail: ana.francisco@terra.com.br
} 
are part of. We will show that contemporaneity is characterized by a culture that privileges and maximizes pleasure, detachable relationships, fight against time, high competitiveness and high consumism. We will point out that contemporaneity has produced a subjectivity constructed on the lack of references, as well as evidence that these human relations are becoming more fragile as time passes, waiting that the deepening of this thematic can contribute to point out the roll of clinical psychologist in this context..

Keywords: Loving relations; contemporaneity; culture; subjectivity; clinical psychology.

A idéia de refletir mais profundamente sobre este tema teve início com a observação clínica da alta freqüência dos desencontros das pessoas em suas relações amorosas. O discurso de querer amar e ser amado, muitas vezes, encontra-se dissociado do desejo de se comprometer, de aceitar as diferenças e de fazer escolhas.

Percebemos que estamos cada vez mais distantes de nós mesmos e dos outros. Se olharmos ao nosso redor, verificaremos que as relações humanas estão cada vez mais frágeis. Parece que estamos, dia a dia, perdendo a capacidade de nos responsabilizar pelo mundo em que desejamos viver e, por conseguinte, de nos indignarmos com situações desumanizantes assistidas cotidianamente. Salta aos nossos olhos o quanto as pessoas vivem em seus limites, exigindo-se fazer parte de um modo de ser cruel e agonizante que incita a buscar prazeres imediatos, relacionamentos descartáveis, a agir de modo competitivo e a lutar contra o tempo. Será que estes aspectos não favorecem os desencontros nas relações amorosas?

Antes de aprofundarmos esta questão, precisamos refletir acerca da possibilidade de se encontrar uma definição precisa que dê conta da abrangência dos diversos significados que o termo relação amorosa pode comportar. Considerando que a nossa proposta é abordar o tema das relações amorosas na contemporaneidade, decidimos iniciar a tentativa de conceituação realizando um breve levantamento de estudos sobre o tema, investigando o significado do termo tanto para o senso comum, através do que é veiculado à Internet, bem como por trabalhos científicos desenvolvidos por profissionais de diferentes áreas do conhecimento.

Um fato que merece destaque é o grande interesse que o tema provoca. $\mathrm{O}$ termo relações amorosas pode ser encontrado desde sites de horóscopo até os 
Compêndios de Psiquiatria. Percebe-se, ainda, certa tendência para se vincular o termo relações amorosas com afeto e com intimidade. Evidenciamos, finalmente, a existência de um certo consenso sobre a importância do afeto para o processo de crescimento emocional, em que se ressalta a afetividade como ingrediente fundamental para a qualidade de vida.

É significativa a quantidade de sites GLBT (gays, lésbicas, bissexuais e transgêneros) em defesa da diversidade sexual e da legitimação de seus direitos, bem como a preocupação de advogados, juízes e desembargadores em reconhecer a legalidade das relações amorosas entre pessoas do mesmo sexo no Brasil. Também merece destaque o fato de que, apesar de ainda haver muito preconceito e discordâncias, há uma parcela razoável de profissionais nessa área que se propõem a lutar pela legitimação das relações homoafetivas, a debater questôes como direito à adoção e herança e a analisar o afeto como relevante fator jurídico nas relações familiares, especialmente nas famílias homoafetivas.

Um outro aspecto importante é que com o novo Código Civil, criado pela Lei 10.406 de 10/01/2002 e em vigor desde 11/01/2003, os profissionais da área jurídica constataram a necessidade de revisão acerca da responsabilidade civil das partes decorrentes do término das relações amorosas. Como afirma Simão (2003): “[...] A idéia de casamento como algo indissolúvel ruiu na década de 70 com a possibilidade do divórcio no Brasil. Nessa toada, as relações pessoais se efemerizaram, passando a assumir um caráter de imediatividade”.

É interessante que quanto mais pesquisamos, mais sólida éa nossa constatação de que a afetividade está presente em tudo, faz parte do humano, independentemente de raça, gênero ou situação de sofrimento psíquico. Inclusive pesquisas realizadas no Museu da Imagem do Inconsciente demonstraram a permanência viva da afetividade nos esquizofrênicos, contrariando um dos chavões da Psiquiatria Tradicional, que frisa o embotamento afetivo progressivo desses indivíduos.

Chama a atenção o alto índice de sites acerca das relações amorosas no mundo virtual e o fato curioso e instigante de que as relações amorosas são abordadas, freqüentemente, como sinônimos de relaçōes sexuais, o que nos leva a refletir sobre este reducionismo, sobretudo, na contemporaneidade.

Uma questão que também merece ser destacada diz respeito à precariedade dos vínculos afetivos, atualmente enfocada como um dos muitos problemas que afetam a vida conjugal. Tem sido recorrente, na clínica, a chamada Síndrome do Comportamento de Hospedagem (SCH). Nesta síndrome, como analisa Siqueira (2005), na rotina do relacionamento, a dificuldade 
de manter o vínculo afetivo é tão forte que se instala um verdadeiro abismo entre os parceiros.

Mas, será que falar de amor é, necessariamente, falar de afeto? Em tese, deveria ser. Nos tempos de hoje, talvez não seja. Explicamos por quê: estamos vivendo a angústia de um tempo que parece não oferecer muitas perspectivas de futuro. Construímos um mundo sujeito à mudanças extremamente rápidas e imprevisíveis, com as quais, muitas vezes, não conseguimos lidar. O fato de nos depararmos com tantas mudanças, constantes e, por vezes, violentamente, parece afetar a nossa capacidade de amar e de estarmos disponíveis para nos relacionarmos com nós mesmos e com os outros. Surgem novas formas de se relacionar e, conseqüentemente, novas redefinições do que vem a ser amor, afeto e relações amorosas.

O que outrora foi definido como amor romântico, cantado em versos e prosa, incitado pela Literatura, poesia e tantos outros recursos artísticos, parece ter se dissipado, se diluído, se transformado, como define Bauman (2004), em Amor Líquido. Não é nossa intenção apologizar o amor romântico através de um discurso saudosista a fim de evocar um tempo que já se foi. Até porque o amor romântico carrega uma ideologia que aponta para o fato de que não é ele a salvação para a escassez de afeto presente em muitas das relações humanas contemporâneas. É importante esclarecermos, também, que não desejamos confundir a perda do ideal romântico com a presença da falta de vínculos afetivos ou o que é pior, mais sério e mais grave, com a presença de vínculos perversos.

Podemos nos perguntar: o que nos resta fazer? Ficar como espectadores ou tentar nos debruçar sobre a questão para que possamos melhor compreendêla, questioná-la e principalmente, lidar com ela. Pois bem, a nossa intenção é problematizar o que hoje se compreende como amor e em quais tipos de vínculos se baseiam as relaçóes amorosas contemporâneas.

Como forma de explicitar esta argumentação, tomamos por empréstimo a definição adotada por Jurandir Freire Costa:

[...] O amor é uma crença emocional, e como toda crença, pode ser mantida, alterada, dispensada, trocada, melhorada, piorada ou abolida [...] Nenhum de seus constituintes afetivos, cognitivos ou conativos é fixo por natureza. Tudo pode ser recriado, se acharmos que assim deve ser, em função do que julgarmos melhor para todos e cada um de nós (COSTA, 1998, p. 12).

Desde esta perspectiva, as diferentes formas assumidas pelo amor são construções históricas e culturais, modificando-se de acordo com o cenário em que 
se apresenta. Em cada época, uma forma de amar e se relacionar se delineiam na paisagem da qual faz parte.

Como observa Bauman:

[...] O amor e a morte não têm história própria. São eventos que ocorrem no tempo humano - eventos distintos, não conectados com eventos similares, a não ser na visão de instituições ávidas por identificar - por inventar - retrospectivamente essas conexões e compreender o incompreensível (BAUMAN, 2004, p. 17).

Giddens (1993) sugere que o termo relacionamento, significando um vínculo emocional próximo e continuado com outra pessoa, só chegou ao uso geral em uma época relativamente recente, caracterizada pela ascensão do amor romântico. Foi a partir do século XVIII que o amor romântico se torna o ideal de casamento e o erotismo entra em cena. É a valorização do amor individual presente na ideologia burguesa que estabelece o casamento por amor, com predomínio do erotismo na relação conjugal, tornando o amor romântico a "marca registrada" da cultura ocidental.

Entretanto, os ideais de amor romântico começaram a se fragmentar com o declínio do controle sexual dos homens sobre as mulheres refletidos na emancipação sexual e na autonomia feminina. As mudanças que vêm ocorrendo nas relações amorosas ao longo da modernidade resultaram em transformações radicais na intimidade e na vida pessoal dos indivíduos.

Como também observa Jurandir Freire Costa (1998): “[... No presente o cenário mudou. $\mathrm{O}$ valor de amor foi hiperinflacionado e sua participação na dinâmica do bem comum chegou quase ao ponto zero [...]” (p. 19-20). Vale ressaltar que enquanto o amor foi emblema do cuidado com as geraçôes, da harmonia entre sexos desiguais e da família como célula da sociedade, guardou a transcendência que o protegia do tempo e do uso. Porém, quando se tornou um sentimento a mais na dieta dos prazeres a quilo, passou a ser visto como qualquer coisa ou pessoa na cultura do consumo: perdeu o interesse, lata do lixo.

Para uma melhor compreensão de algumas dessas características nas relações amorosas contemporâneas, faz-se necessário uma breve cartografia subjetiva cultural deste tempo, na medida em que as relações amorosas são parte/ expressões/espelhos desta cartografia.

Refletir acerca da situação das relações amorosas na contemporaneidade implica, necessariamente, em considerarmos que estas relações fazem parte de uma paisagem social, cultural e subjetiva com nuances e contornos próprios. 
Deste modo, é imprescindível enfocar a relação existente entre cultura e produção de subjetividade, destacando os aspectos que, na contemporaneidade, favorecem os desencontros nas relações amorosas.

Para Boaventura de Souza Santos (1996), a contemporaneidade vive em um momento intervalar. Somos atravessados culturalmente tanto por resíduos da modernidade como por configuraçóes da pós-modernidade, vivendo, inclusive, os conflitos próprios desse período de transição.

$\mathrm{Na}$ atualidade existem inúmeras situações que propiciam o recuo da proximidade contínua, pessoal, direta, face a face e que acentuam o isolamento, a solidão e a indisponibilidade para nos relacionarmos uns com os outros, inclusive afetiva e amorosamente.

Bauman refere que, atualmente, os lares já não são mais ilhas de intimidade.

[..] Nós entramos em nossas casas separadas e fechamos a porta, e, então, entramos em nossos quartos separados e fechamos a porta. A casa torna-se um centro de lazer multiuso em que os membros da família podem viver, por assim dizer, separadamente, lado a lado (BAUMAN, 2004, p.84).

No que diz respeito à evolução no campo das comunicações, este autor argumenta, ainda, que o que deveria ser apenas uma revolução, também, possibilitou desencontros entre as pessoas, tornando desnecessário que as pessoas se olhem nos olhos.

Se pensarmos nas relações amorosas, constataremos o quanto o amor romântico e seus ideais, apesar de persistirem como ideal de vida e felicidade, povoando o imaginário de muitos, tem se transformado, cada vez mais, em amor líquido, tal como conceitua Bauman. $\mathrm{O}$ termo líquido refere-se à liquidez, no sentido de rentável. Serve, também, para designar uma sociedade consumista, imediatista, fluida e excessivamente preocupada com o tempo.

Perceberemos, também, que os vínculos estabelecidos nas relações amorosas atuais, são frouxamente atados para que possam ser desfeitos, sem grandes delongas, sempre que os cenários mudarem, o que na modernidade líquida, decerto, ocorrerá repetidas vezes.

$\mathrm{Na}$ experiência clínica, enquanto psicoterapeuta, comumente observamos o quanto as pessoas dedicam atenção especial em suas vidas às relações amorosas e o quanto se concentram nas satisfaçōes que esperam obter destas. A grande questão é que por mais que muitos desejem uma relação amorosa satisfatória - dentro do que cada um julga que satisfaz - a grande maioria apresenta uma dissociação entre o desejo de se comprometer com o outro e o empenho em atitudes para que isto ocorra. 
Em uma época em que tudo é permitido, em que "o arbitrário tem força de lei" (BRECHT, s/d), parece haver uma grande dificuldade, como sugere Melman (2003), de se renunciar ao gozo permanente, de sustentar as conseqüências de uma escolha.

Essa idéia nos parece pertinente na medida em que líquido adquire o sentido de liquidez, de rentável, o que é relevante para a questão que estamos investigando. Em um mundo onde predomina a maximização do prazer (BAUMAN, 2004) ou uma atração por um gozo excessivo (MELMAN, 2003), o amor líquido se configura como um sintoma da nossa época.

Não se pode reinventar o passado, mas é preciso projetar o futuro. Se o amor romântico foi uma construção histórica e cultural que respondia às demandas de uma determinada configuração familiar e social de uma dada época, estas configurações, por serem outras, não impõem uma banalização das relações amorosas, mas, ao contrário, a busca de novos sentidos (direções) e significações.

Compreendendo a clínica como uma ação política porque comprometida com o desejo, a construção de novas formas desejantes forjar-se-ia na aspiração de relações amorosas em que “[...] amar é contribuir para o mundo, cada contribuição sendo o traço vivo do eu que ama [...] amar significando estar a serviço, colocar-se à disposição" (op.cit. p, 24). Desde esta perspectiva, qualquer forma de amor vale a pena quando o amor não é pequeno, mesquinho, atendendo a interesses próprios. É possível crescer com o outro, independente de sua raça, cor, gênero e da configuração familiar construída para se expressar esta relação amorosa. Pensar a clinica como dispositivo capaz de promover uma mudança de mentalidades é apostar em sua força de transformação dirigida à potencialização da vida que tenha como fundamento a construção de relações amorosas.

\section{Referências bibliográficas}

BAUMAN, Z. Amor Líquido: Sobre a fragilidade das relações humanas. Rio de Janeiro: Jorge Zahar Ed., 2004.

BRECHT, B. Antologia Poética. Disponível em: <http//www.cultura brasil.pro.br/buchtantologia>

COSTA, J.F. Sem fraude nem favor: estudos sobre o amor romântico. Rio de Janeiro: Rocco, 1998.

GIDDENS, A. A Transformação da Intimidade: Sexualidade, Amor e Erotismo nas Sociedades Modernas. Tradução de Magda Lopes. São Paulo: Editora da Universidade Estadual Paulista, 1993. 
MELMAN, C. O Homem sem gravidade: gozar a qualquer preço. Rio de Janeiro: Companhia de Freud, 2003.

SANTOS, B. de S. Pela mão de Alice: O Social e o Político na Pós-Modernidade. 2a Ed. São Paulo: Cortês, 1996.

SIMÃO, J.F. A quebra das relações afetivas e os danos morais decorrentes: o ficar, o namoro e o casamento. Net, São Paulo, 2003. Seção Artigos do Simão. Disponível em: <http://www.professorsimao.com.br>. Acesso em: 03/03/2007.

SIQUEIRA, N. A.C. Dificuldades no Relacionamento conjugal ocasionadas pela Síndrome do Comportamento de Hospedagem. Net, São Paulo, 19 jan.2005. Seção Colaboradores. Disponível em: <http://www. psiqweb.med.br>. Acesso em: 03/03/2007. 